\title{
Role of the JAK-STAT pathway in proliferation and differentiation of human hypertrophic scar fibroblasts induced by connective tissue growth factor
}

\author{
LING TAO*, JIANYI LIU*, ZHE LI, XIA DAI and SHIRONG LI \\ Department of Plastic and Reconstructive Surgery, Southwestern Hospital, \\ Third Military Medical University, Chongqing 400038, P.R. China
}

Received May 12, 2010; Accepted August 16, 2010

DOI: $10.3892 / \mathrm{mmr} .2010 .349$

\begin{abstract}
The aim of this study was to investigate whether the JAK-STAT pathway participates in the processes of proliferation and differentiation induced by connective tissue growth factor (CTGF) in human hypertrophic scar fibroblasts (hHSF). hHSF were grown as primary cultures, then treated with or without CTGF. Western blotting was used to detect JAK1, JAK2, JAK3, TYK2, STAT1, STAT2, STAT3, STAT4, STAT5 and STAT6 protein expression in the hHSF at various time points after stimulation with CTGF. Immunofluorescence and the electrophoretic mobility shift assay (EMSA) were used to identify the interacting signalling molecules and to investigate their activation, respectively. After the signalling molecules of interest were selected, a specific inhibitor (STAT1 ASODN) was used to block the JAK-STAT pathway. The MTT assay was used to detect the proliferation of hHSF, and differentiation was assessed by evaluating changes in $\alpha$-SMA expression by RT-PCR. Based on the results of Western blotting, immunofluorescence and EMSA, proliferation and differentiation were much higher in hHSF treated with CTGF $(p<0.05)$. After blocking the pathway with STAT1 ASODN, hHSF proliferation was markedly, though not entirely, inhibited, while $\alpha$-SMA expression was not significantly altered. JAK1 and STAT1 are therefore likely to participate in the proliferation and differentiation of hHSF induced by CTGF. However, though the STAT1 signalling pathway plays a key role in the CTGF-induced proliferation of hHSF, it is not the only pathway controlling this
\end{abstract}

Correspondence to: Professor Shirong Li, Department of Plastic and Reconstructive Surgery, Southwest Hospital, Third Military Medical University, 29 Gaotanyan Main Street, Shapingba District, Chongqing 400038, P.R. China

E-mail: lishirong.cqzx@yahoo.com.cn

${ }^{*}$ Contributed equally

Key words: connective tissue growth factor, human hypertrophic scar fibroblast, STATs, JAKs, proliferation, differentiation process. JAK1 may be an upstream element of STAT1, and may also participate in the CTGF-induced proliferation of hHSF. These results elucidate the signal transduction mechanism of CTGF-induced hHSF proliferation, and may aid in the development of a novel method for the inhibition of scar fibrosis and contraction.

\section{Introduction}

Fibroblasts are the main cells affecting the growth of hypertrophic scars (HS), and their proliferation and differentiation are regulated by growth factors. Connective tissue growth factor (CTGF) was recently identified as a growth factor that intensively promotes fibrosis. In a previous study, our prophase results showed that CTGF stimulated the proliferation and differentiation of human hypertrophic scar fibroblasts (hHSF) (1); however, the signal transduction mechanisms behind this effect have yet to be determined. Previous studies have indicated that JAK-STATs participate in numerous diseases through the accommodation of multiple signal transduction pathways $(2,3)$. However, there are few reports on the relationship between JAK-STATs and the CTGF-induced proliferation and differentiation of hHSF. Therefore, we investigated the activation of JAK-STATs in hHSF stimulated by CTGF in order to identify the functional signalling molecules in this pathway.

\section{Materials and methods}

Patients and samples. Samples were obtained from 6 patients that developed a hypertrophic scar 3-12 months post-surgery. The hypertrophic scars were red and hard to the touch, and displayed hyperremia and pruritus. Research was carried out following international and national regulations. The study was approved by the Local Ethics Committee of our institution, and all patients gave informed written consent.

Cell cultivation. hHSF were cultured in $10 \%$ calf serum (CS) (Hali Bioengineering Co., Chengdu, China), DMEM (Gibco, USA), $0.25 \%$ trypsin (Gibco) and phosphate buffered saline (PBS) (Zhongshan Jinqiao Biotechnology Co., Ltd., Beijing, China). 
For the intital experiments, cells were divided into two groups: Group 1, hHSF without CTGF (control); and Group 2, hHSF with CTGF (experimental group).

Stimulation of hHSF by CTGF. DMEM was combined with $10 \%$ CS, then DMEM without CS was added. The cells were starved for 18-24 h, then the supernatant was poured off. DMEM was added to $10 \mathrm{ng} / \mathrm{ml} \mathrm{CTGF}$, and then the fibroblasts were cultured under standard conditions $\left(37^{\circ} \mathrm{C}, 5 \% \quad \mathrm{CO}_{2}\right.$, humidity $95-100 \%$ ) for $0,5,10,20,30,45,60$ and $90 \mathrm{~min}$, followed by protein extraction.

Western blotting. To detect the activation of the JAK-STAT proteins in the two groups, Western blotting was conducted using bovine serum albumin (BSA), rabbit antibodies (all from Cell Signaling Technology, Beverly, MA, USA, with the exception of phospho-JAK3 and phospho-STAT4, which were from Santa Cruz Biotechnology Inc., Santa Cruz, CA, USA), $0.45 \mu \mathrm{m}$ polyvinylidene difluoride (PVDF) membranes (Millipore, Billerica, MA, USA), a Bio-Rad electrophoresis apparatus, electrotransfection apparatus, and gel imaging system (all from Bio-Rad Laboratories, Hercules, CA, USA), and developer and fixer (analytical grade; Pierce, Rockford, IL, USA). Western blotting was conducted according to routine methods using monoclonal and polyclonal antibody concentrations of 1:1000 and 1:4000, respectively (1).

The results of Western blotting were analysed using single-factor analysis of variance (ANOVA) and the t-test with SPSS 10.0 statistical analysis software. Data are presented as the mean $\pm \mathrm{SD}$. A value of $\mathrm{p}<0.05$ indicated a significant difference.

Immunofluorescence staining protocol. To determine the nuclear translocation of STAT1 in the two groups, immunofluorescence analysis was conducted using $4 \%$ paraformaldehyde fixative, $0.01 \mathrm{~mol} / 1 \mathrm{PBS}$ (pH 7.4), BSA, Triton X-100, phosphoSTAT1 rabbit monoclonal antibody (Cell Signaling Technology) and 5'-FITC-labelled goat anti-rabbit IgG. A routine indirect staining method was used (4). In a previous study (5), STAT1 reached its activation peak at $30 \mathrm{~min}$; therefore, $30 \mathrm{~min}$ was selected as the activation period. phospho-STAT1 antibody was diluted to a concentration of $1 \mu \mathrm{g} / \mathrm{ml}$ in PBS with $0.1 \%$ BSA and $0.3 \%$ Triton X-100, then incubated at $37^{\circ} \mathrm{C}$ overnight. The FITC-labelled goat anti-rabbit $\operatorname{IgG}$ was diluted by the same method, and was incubated at $37^{\circ} \mathrm{C}$ for $1 \mathrm{~h}$.

The results of immunofluorescence were observed using the Bio-Rad Radiance 2000 Confocal Laser Scanning Fluorescence Microscope. Slides were scored as: +++ to ++++ , marked bright green staining; ++, bright fluorescent green staining; + , weak but clear staining; \pm , very weak, doubtful staining; and -, no staining.

Electrophoretic mobility shift assay (EMSA). To determine the DNA-binding ability of STAT1, a DNA oligonucleotide probe containing the high-affinity sis-inducible element (m67 variant) was used, which is capable of inducing the formation of a homodimer or heterodimer sis-inducing factor (SIF) complex with phospho-STAT1. The upstream primer sequence (5'-CATTTCCCGTAAATC-3') was paired with the downstream sequence (5'-TGCCCTTTACGGGCT-3'). The
y-32P-ATP-labelled probe was added to EMSA buffer at a final concentration of $1.75 \mathrm{mmo} / 1$.

First, the DNA-binding ability of STAT1 in the presence of various concentrations of CTGF $(0,5,7.5,10$ and $15 \mathrm{ng} /$ $\mathrm{ml}$ ) was determined. Binding was observed to peak at a CTGF concentration of $10 \mathrm{ng} / \mathrm{ml}$. Therefore, in the next experiment, STAT1 binding ability and persistence were noted at various time points $(0,10,20,30,45,60,90$ and $120 \mathrm{~min})$ at the CTGF concentration of $10 \mathrm{ng} / \mathrm{ml}$. Fixation reactions with tales doses (td) of nuclear protein samples were obtained using $10 \mu \mathrm{g}$ nuclear protein, $5 \mathrm{X}$ fixation buffer [20\% glyceryl alcohol, $5 \mathrm{mmol} / 1 \mathrm{MgCl}_{2}, 2.5 \mathrm{mmol} / 1$ EDTA, $2.5 \mathrm{mmol} / 1$ DTT, $250 \mathrm{mmol} / \mathrm{l} \mathrm{NaCl}, 50 \mathrm{mmol} / \mathrm{l}$ Tris-HCI (pH 7.5), and $0.25 \mathrm{mg} / \mathrm{ml}$ poly $(\mathrm{dI}-\mathrm{dC}) \cdot \operatorname{poly}(\mathrm{dI}-\mathrm{dC})]$. Antibody $(4 \mu \mathrm{g} /$ $\mu 1)$ was added to $2.5-5 \mu \mathrm{g}$ nuclear protein in the SuperShift System. Electrophoresis was conducted at $300 \mathrm{~V}$ at $4^{\circ} \mathrm{C}$ for 2-3 h.

STAT1 ASODN transfection. STAT1 ASODN was transfected into the hHSF using Lipofectamine ${ }^{\text {Tx }} 2000$ with the 5'-FITClabelled primer 5'-CCACTgAgAgACATCCTgCCACC $3 '$ (phosphorothioate oligodeoxynucleotides). The fibroblasts were cultured in a 6-well plate until reaching $70-80 \%$ confluence. The antisense oligonucleotides were dissolved in $47 \mu \mathrm{l}$ $\mathrm{ddH}_{2} \mathrm{O}$, then divided into 2 groups: Group 1, Lipofectamine $2000(20 \mu \mathrm{l})+$ serum-free medium (SFM) without antibody $(480 \mu \mathrm{l})$; and Group 2, STAT1 ASODN $(2.8 \mu \mathrm{l})+\mathrm{SFM}$ without antibody $(250 \mu \mathrm{l})$. Cells were left to stand for $5 \mathrm{~min}$. Subsequently, $250 \mu 1$ of the Group 1 solution was added to the Group 2 solution, then the mixture was agitated for $15 \mathrm{~min}$, placed into a 6-well plate and labelled, and incubated for $15 \mathrm{~h}$.

Detection of differences in the CTGF-induced proliferation and differentiation of $h H S F$ after STATI ASODN transfection. hHSF were further divided into groups as follows: Group 1, STAT1 ASODN + CTGF; Group 2, CTGF alone; Group 3, STAT1 ASODN alone; and Group 4, control group using GAPDH as the reference gene. The MTT assay was used to detect the proliferation of hHSF in all four groups. To determine the extent of differentiation, STAT 1 and $\alpha$-SMA levels were evaluated by RT-PCR (Takara, Kyoto, Japan) using the primers STAT1: GTGATGAACATGGAGGA GTC (forward), and GCCCATCGTGCACATGGT (reverse); $\alpha$-SMA: CTGAAGAGCATCCGACAC (forward), and GAC TCCATCCCAATGAAAG (reverse); GAPDH: GCAGTGFCA AAGTGGAGATTG (forward), and GCAGAAGGGGCGGA GATGAT (reverse). The RT mixture was composed of $8 \mu \mathrm{l}$ $\mathrm{MgCl}_{2}, 4 \mu 1$ 10X RT buffer, $4 \mu 1 \mathrm{dNTP}, 1 \mu 1$ RNase suppressor, $2 \mu 1$ oligodT and $2 \mu 1$ AMV-RT, added to $10.5 \mu 1$ RT buffer, $1 \mu \mathrm{g}$ RNA and DEPC $\mathrm{ddH}_{2} \mathrm{O}$, for a total volume of $20 \mu \mathrm{l}$. Reaction conditions were $50^{\circ} \mathrm{C}$ for $30 \mathrm{~min}, 99^{\circ} \mathrm{C}$ for $5 \mathrm{~min}$ and $5^{\circ} \mathrm{C}$ for $5 \mathrm{~min}$, followed by denaturing at $94^{\circ} \mathrm{C}$ for $2 \mathrm{~min}$, then 30 cycles of denaturing at $94^{\circ} \mathrm{C}$ for $30 \mathrm{sec}$, annealing at $60^{\circ} \mathrm{C}$ for $30 \mathrm{sec}$, and elongation at $72^{\circ} \mathrm{C}$ for $30 \mathrm{sec}$, and a final elongation at $72^{\circ} \mathrm{C}$ for $10 \mathrm{~min}$ (STAT1 ASODN or $\alpha$-SMA), or denaturing at $94^{\circ} \mathrm{C}$ for $2 \mathrm{~min}$, then 30 cycles of denaturing at $94^{\circ} \mathrm{C}$ for $30 \mathrm{sec}$, annealing at $55^{\circ} \mathrm{C}$ for $30 \mathrm{sec}$ and elongation at $72^{\circ} \mathrm{C}$ for $30 \mathrm{sec}$, and a final elongation at $72^{\circ} \mathrm{C}$ for $10 \mathrm{~min}$ $(\mathrm{GAPDH})$. Tranfected hHSF were maintained at $4^{\circ} \mathrm{C}$. 


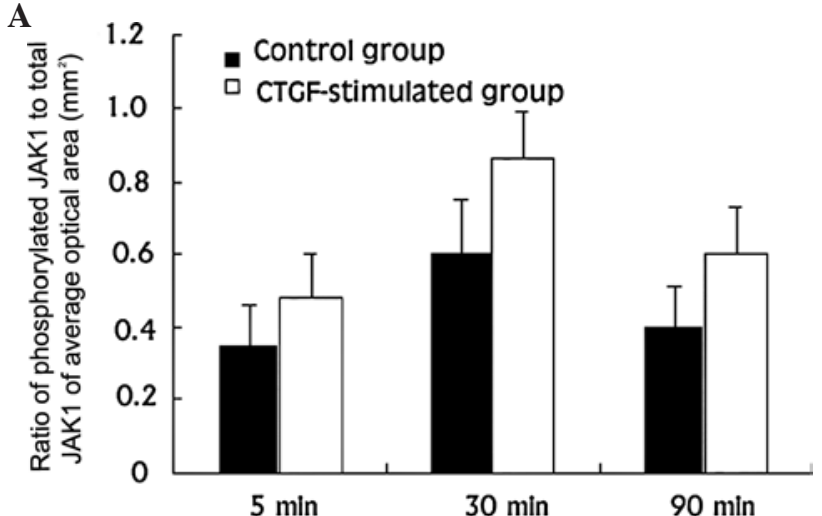

B

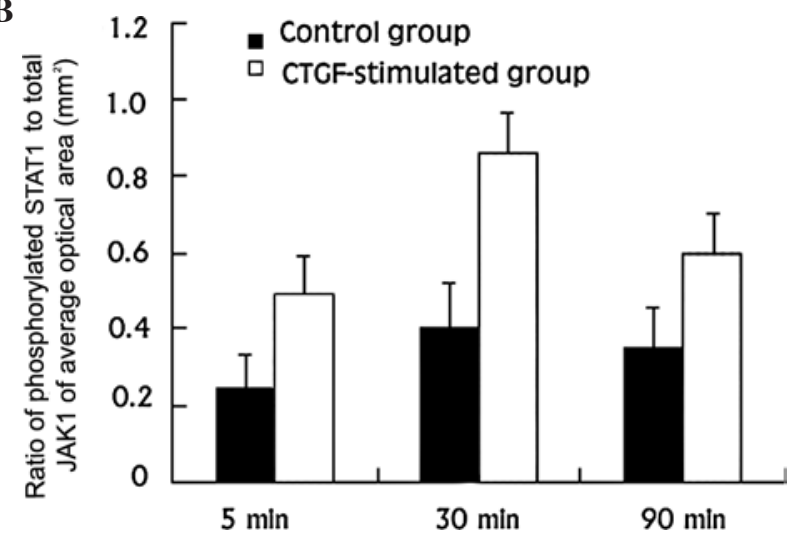

Figure 1. Results of Western blotting showing the expression of (A) JAK1 and (B) STAT1 in hHSF after stimulation with connective tissue growth factor.

Electrophoresis was conducted at $100 \mathrm{~V}$ for $30 \mathrm{~min}$ with $10 \mu \mathrm{l}$ PCR production and $2 \mu 110 \mathrm{X}$ loading buffer. Images were captured on a Gel Doc 1000 system.

\section{Results}

Since an increase in proliferation and in the expression of $\alpha$-SMA was observed in hHSF stimulated by CTGF, the JAK-STAT pathway was considered to be activated. Two forms of JAK-STAT protein (t-) were identified: non-phosphorylated and phosphorylated (p-). The phosphorylated proteins appeared early during the cultivation, increased gradually over time, peaked at $30 \mathrm{~min}$, and decreased after $30 \mathrm{~min}$.

Among the proteins tested, only the ratio of p-JAK1/ t-JAK1 to p-STAT1/t-STAT1 was increased following CTGF stimulation (Fig. 1). Time points analysed were 5, 30 and $90 \mathrm{~min}$.

The results of immunofluorescence revealed that phosphorylated STAT1 peaked at $30 \mathrm{~min}$. The control group $(++)$ (Fig. 2a) exhibited bright fluorescent green staining, and equal distribution of staining between the nucleus and cytoplasm. The CTGF group (+++ to ++++$)$ (Fig. 2b) exhibited marked bright green staining, and the nuclear fluorescence was much brighter than the cytoplasmic fluorescence.

EMSA was used to detect the DNA binding ability and persistence of STAT1. The ability of STAT1 to bind DNA was correlated to the concentration of CTGF. Binding increased gradually at CTGF concentrations of $0 \mathrm{ng} / \mathrm{ml}, 5 \mathrm{ng} / \mathrm{ml}, 7.5 \mathrm{ng} /$
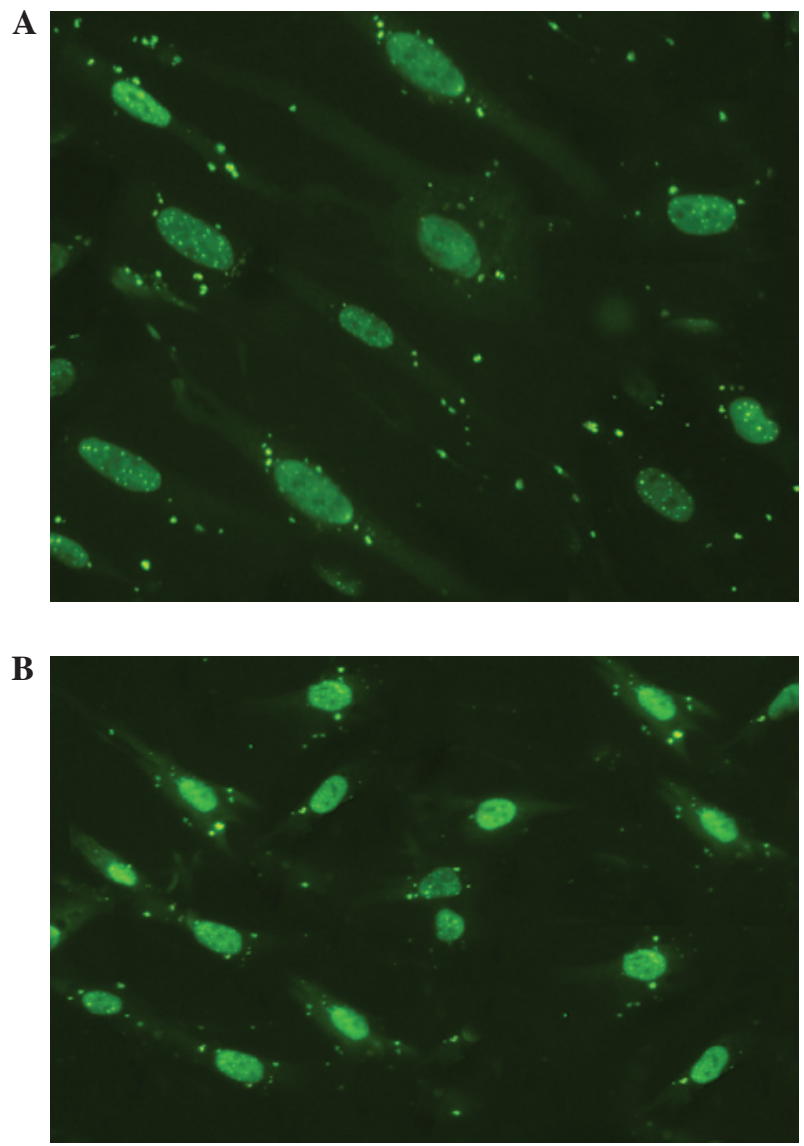

Figure 2. Immunofluorescence staining showing the distribution of STAT1 in (A) the control group (magnification, x200) and (B) the CTGF group (magnification, $\mathrm{x} 100)$.

$\mathrm{ml}, 10 \mathrm{ng} / \mathrm{ml}$ and $15 \mathrm{ng} / \mathrm{ml}$, peaked at $10 \mathrm{ng} / \mathrm{ml}$ CTGF, then decreased (Fig. 3a).

hHSF were stimulated with $10 \mathrm{ng} / \mathrm{ml}$ CTGF and binding was evaluated at various time points $(0,10,20,30,45,60$, 90 and $120 \mathrm{~min})$. SIF was found to be activated at $10 \mathrm{~min}$, peaked at 45-60 min and decreased gradually after $60 \mathrm{~min}$. The binding ability of the CTGF group was much higher than that of the control group (Fig. 3b).

STAT1 ASODN was successfully transfected into the hHSF by RT-PCR, and showed stable expression in these cells. MTT was used to detect the proliferation of hHSF before and after transfection with STAT1 ASODN. The proliferation of hHSF was found to be significantly inhibited after ASODN transfection $(\mathrm{p}=0.05)$ (Fig. $4 \mathrm{a})$. There was no significant change in the expression of $\alpha$-SMA before and after blocking STAT1 ASODN (p=0.05) (Fig. 4b).

\section{Discussion}

Hypertrophic scars are caused by localised concrescence after damage to the dermis (1). Their pathological characteristics are over-proliferation, differentiation of hHSF and over-deposition of extracellular matrix proteins, in particular collagen (1). Elucidating the mechanims behind the development of hypertrophic scars would aid in their prevention in the field of trauma medicine and in reconstructive burn care. The main strategy for the inhibition of fibrosis is the suppression of the 
A

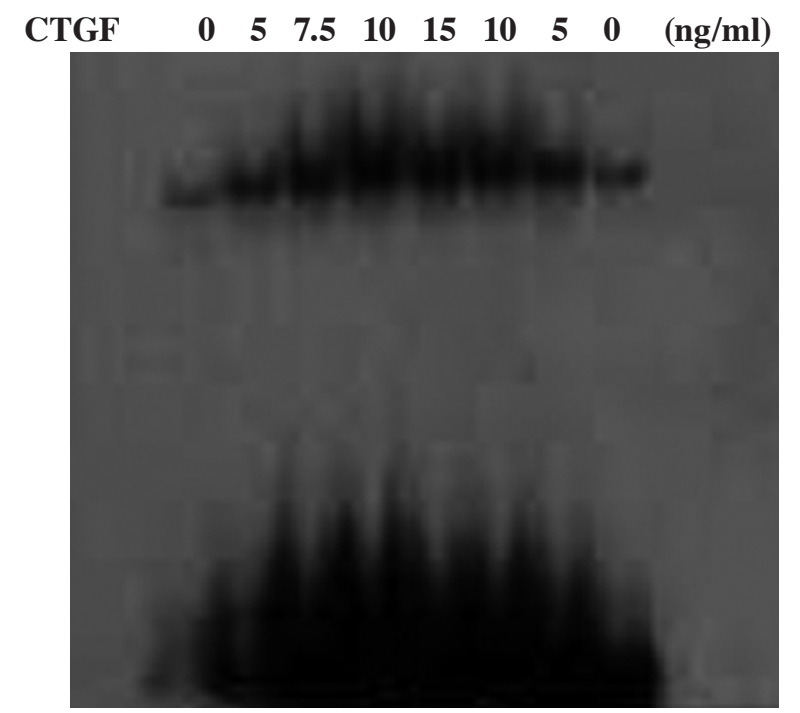

B

Control

CTGF

$\begin{array}{llllllllllllllll}120 & 90 & 60 & 45 & 30 & 20 & 10 & 120 & 90 & 60 & 45 & 30 & 20 & 10 & 0 & (\min )\end{array}$

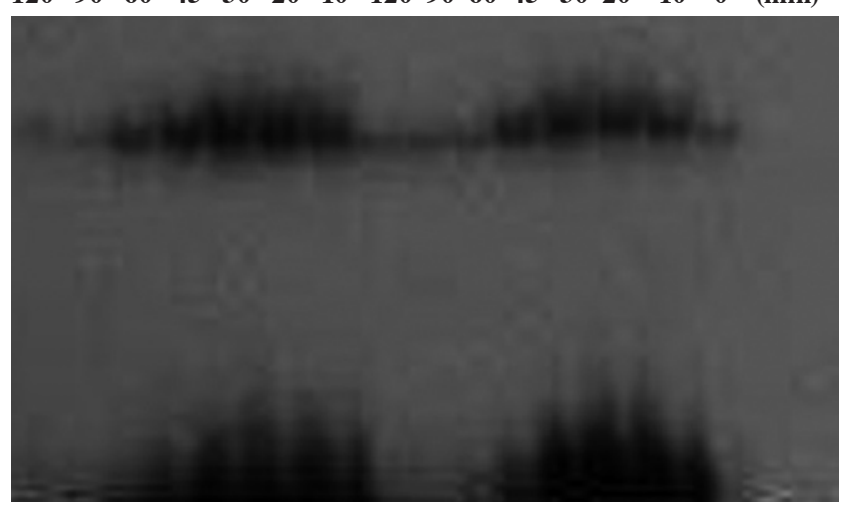

Figure 3. EMSA showing the ability of STAT1 to bind (A) DNA with different concentrations of CTGF, and (B) DNA in the control and CTGF groups.

proliferation and differentiation of hHSF (1). CTGF is a growth factor that specifically and electively interferes in the formation of connective tissue by promoting fibrosis and stimulating hHSF to differentiate into myofibroblasts (1) The inhibition of CTGF is a specific and effective method for preventing organ fibrosis. However, there are few reports discussing its signal transduction mechanism in hHSF .

The JAK-STAT pathway is a key pathway that participates in cytokine signal transduction, many physiological functions, including haematogenesis, and numerous pathological diseases, including tumours, arthritis deformans, brain injuries and bronchial asthma $(2,3,6,7)$. The JAK-STAT pathway also participates in the proliferation, differentiation and aging of nerve cells, and has an intimate correlation with the pathological processes of the nervous system (7). Numerous cytokines, including interferon- $\alpha,-\beta$ and $-\gamma$, and interleukin- $2,-4$ and -6 , and growth factors, including epidermal and platelet-derived growth factors, growth hormones, and leptin, regulate the proliferation and differentiation of cells through the JAK-STAT pathway. JAK-STATs are affected by the expression of CTGF induced by advanced glycation end-product (AGE) in renal interstitial fibroblasts in patients with diabetic nephropathy
A

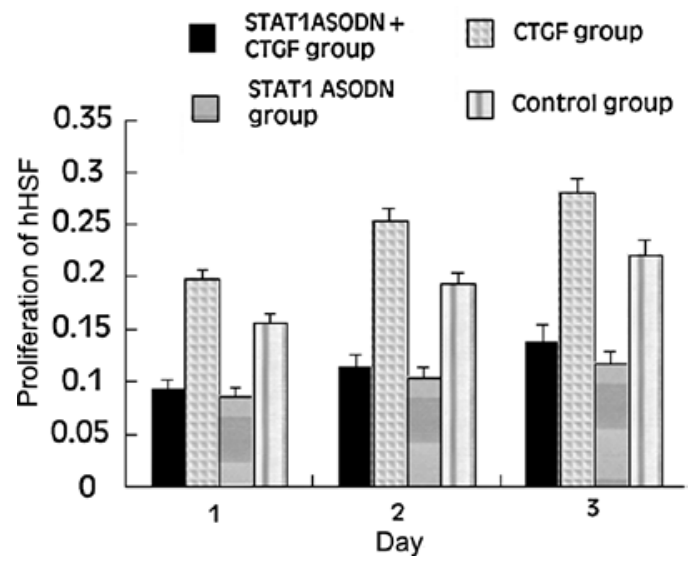

B

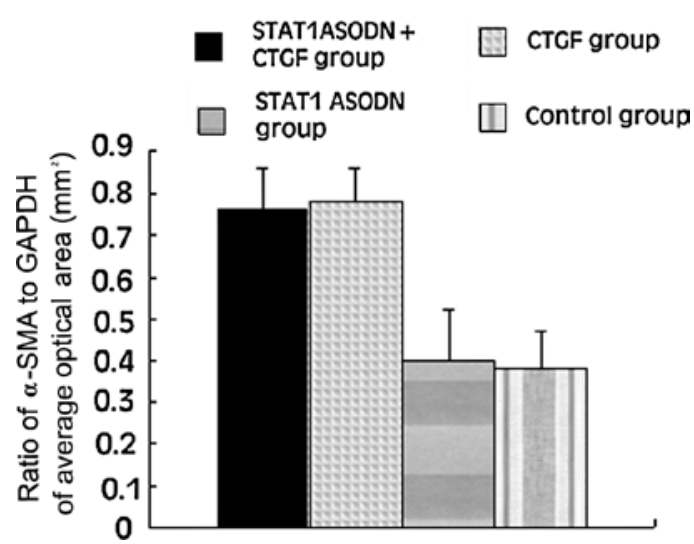

Figure 4. (A) Results of the MTT assay showing hHSF proliferation. (B) Results of RT-PCR showing differences in $\alpha$-SMA RNA expression.

(8). Studies have shown that IL-6, INF- $\gamma$, PDGF and EGF mediate the signal transduction of cell surface receptors to the nucleus and regulate gene transcription through the JAK-STAT pathway. The process involves the phosphorylation of JAKs, cytoplasmic STATs, the formation of SIF compounds, nuclear translocation and binding with SIE (sis-inducing element) in the promoter region.

The present study aimed to examine the role of the JAK-STAT pathway in the proliferation and differentiation of hHSF induced by CTGF. The results indicate that JAK1 and STAT1 activity was increased following CTGF stimulation, and was to some extent correlated with CTGF-induced proliferation and differentiation of hHSF. The fluorescence intensity of phosphorylated STAT1 and the DNA binding ability of STAT1 were markedly increased following the activation of CTGF. The proliferation of hHSF was markedly, but not entirely, inhibited after STAT1 ASODN transfection. $\alpha$-SMA expression before and after blocking STAT1 ASODN, indicating differentiation, was not significantly altered.

In conclusion, STAT1 plays a key role in the CTGFinduced proliferation of hHSF, but is not the only pathway controlling this process. JAK1 may be an upstream element of STAT1, and may participate in the induction of hHSF proliferation by CTGF. These results elucidate the signal transduction mechanism of CTGF-induced hHSF proliferation, and may aid in the development of a novel method for the inhibition of scar fibrosis and contraction. 


\section{Acknowledgments}

This work was supported in part by a grant from the National Natural Science Foundation of China (no. 30400472).

\section{References}

1. Li Z, Li S, Liu J, Dai X, Chen K and Tao L: Connective tissue growth factor promotes transdifferentiation of fibroblasts from human hypertrophic scar in vitro. AAMMT 28: 775-777, 2006.

2. Shi K and Fang M: The relationship between JAK/STAT pathway and physio-/patho- haematogenesis. Medical Recapitulate 8: 225-227, 2002

3. Sun S and Wang $\mathrm{H}$ : The relationship between JAK/STAT pathway and J lung cancer. Int J Respir 26: 313-315, 2006.

4. Xu P: Fluorescence and Immunofluorescence Staining Technique and its Application. 2nd edition. People's Medical Publishing House, Beijing, p103, 2000.
5. Tao L, Li S and Liu J: Effects of connective tissue growth factor in the activation of STATs proteins of human hypertrophic scar fibroblast. Chinese Journal of Aesthetic Medicine 17: 521-523, 2008.

6. Zhai X and Zou Y: The relationship between JAK/STAT pathway and brain injured. Journal of Hebei Medical University 27: 458-460, 2006.

7. Li X: The research advancement of JAK/STAT signal pathway in rheumatoid arthritis. Chinese Journal of Rheumatology 9: 365-366, 2005.

8. Lee CI, Guh JY, Chen HC, Hung WC, Yang YL and Chuang LY: Advanced glycation end-product-induced mitogenesis and collagen production are dependent on angiotensin II and connective tissue growth factor in NRK-49F cells. J Cell Biochem 95: 281-292, 2005. 